\title{
Mathematical Modeling of Mean Flow Stress during the Hot Strip Rolling of Nb Steels
}

\author{
K. MINAMI,") F. SICILIANO Jr., T. M. MACCAGNO and J. J. JONAS
}

Department of Metallurgical Engineering, McGill University, 3450 University Street, Montreal, Canada H3A 2A7. E-mail: JohnJ@MinMet.Lan.McGill.Ca Ibaraki-ken, 314 Japan.

1) On leave from Kashima Steel Works, Sumitomo Metal Industries, Ltd., Hikari, Kashima,

(Received on June 18, 1996; accepted in final form on September 9, 1996)

\begin{abstract}
The mean flow stresses developed during the hot strip rolling of nine grades of $\mathrm{Nb}$ steel have been examined. For this purpose, log data obtained from four different strip mills were converted to mean flow stress using the Sims approach. The results are analyzed and compared to the predictions of a mathematical model that takes microstructural evolution into account. The model is based on the Misaka equation, but incorporates the effects of dynamic, metadynamic, and static recrystallization, and also takes the accumulated strain and $\mathrm{Nb}$ content into account. Excellent agreement between measured and predicted mean flow stress values is obtained over the whole range of rolling temperatures. In addition, the predictions indicate that dynamic, followed by metadynamic, recrystallization takes place in the latter passes of the finishing rolling of some $\mathrm{Nb}$ grades. This generalization applies particularly to the low $\mathrm{Si}$ and high $\mathrm{Mn}$ grades, indicating that the $\mathrm{Si}$ and $\mathrm{Mn}$ concentrations and not only the $\mathrm{Nb}$ level, determine whether or not dynamic and metadynamic recrystallization are observed under hot strip rolling conditions.
\end{abstract}

KEY WORDS: hot strip rolling; Nb steel; mill data; mean flow stress; mathematical model; static recrystallization; dynamic recrystallization; metadynamic recrystallization; accumulated strain; computer spreadsheet.

\section{Introduction}

The mean flow stress (MFS) during hot rolling is the most important factor affecting the control of hot strip mills. It is influenced by the microstructural events that take place, such as static recrystallization (SRX), dynamic recrystallization (DRX), and metadynamic recrystallization (MRX). ${ }^{1)}$ Over the past two decades, many researchers have analyzed the MFS behaviour of $\mathrm{C}-\mathrm{Mn}$ steels, and the results have been successfully applied to the development of process control models for hot strip rolling. However, the MFS behaviour of $\mathrm{Nb}$ grades has been much more difficult to characterize.

In the cases of rod and bar rolling, high strain rates $\left(100-1000 \mathrm{~s}^{-1}\right.$ ), short interpass times (a few tens to a few hundreds of milliseconds), and large strains per pass $(0.4-0.6)$ have been found to favour DRX. ${ }^{2)}$ Because the presence of $\mathrm{Nb}$ in solution leads to the retardation of SRX ${ }^{3)}$ it has been proposed that DRX also occurs during hot strip rolling, particularly in $\mathrm{Nb}$ microalloyed steels. The accumulation of retained work hardening leading to the initiation of DRX during the hot working of $\mathrm{Nb}$ steels was first detected in strip mill simulations. ${ }^{4)}$ More recently, Sarmento and Evans ${ }^{5)}$ and Biglou et al. ${ }^{6)}$ have argued that this sequence of events is also evident in their hot strip mill measurements. It is clear from their results that it is difficult to formulate a single flow stress equation that describes the variation of MFS in all the finishing stands. In this work, the Misaka MFS equation ${ }^{7)}$ was used as a basis for calculating the rolling load that applies to $\mathrm{Nb}$ steels.

The occurrence of DRX by strain accumulation during industrial rolling has been a matter of some debate in the literature ${ }^{8)}$ If DRX occurs in hot strip mills, it should be possible to produce finer austenite grain sizes than are attainable if SRX is the only operative recrystallization process. The aim of the present study was therefore to establish whether or not DRX actually occurs in $\mathrm{Nb}$ grades under industrial conditions. In the later stands of hot strip rolling, when the interpass times are relatively short and the recrystallization kinetics are retarded because of the decrease in temperature, the strains can begin to accumulate, making it possible to initiate DRX. In order to test this hypothesis, hot strip mill data were first converted into the mean flow stresses that apply to each pass. These were then compared with the predictions of a new mathematical model for the MFS in Nb steels. In this way, it was possible to establish that DRX takes place under certain conditions during the hot strip mill finishing of particular $\mathrm{Nb}$ grades.

\section{Materials and Procedure}

\subsection{Mill Log Data}

Industrial rolling data were obtained for nine $\mathrm{Nb}$ steels processed at four different hot strip mills. The rolling data for two $\mathrm{Nb}$ grades (SK1, SK2) were obtained from the Sumitomo (Japan) 7-stand hot strip mill. Similarly, 
Table 1. Chemical compositions of the materials studied. $(w t \%)$

\begin{tabular}{|c|c|c|c|c|c|c|}
\hline & $\mathrm{C}$ & $\mathrm{Mn}$ & $\mathrm{Nb}$ & $\mathrm{Ti}$ & $\mathrm{Al}$ & $\mathrm{Si}$ \\
\hline SK1 & 0.07 & 1.12 & 0.023 & 0.016 & 0.029 & 0.050 \\
\hline SK2 & 0.09 & 1.33 & 0.036 & 0.016 & 0.019 & 0.060 \\
\hline DH1 & 0.06 & 0.65 & 0.020 & - & 0.035 & 0.225 \\
\hline DH2 & 0.06 & 0.65 & 0.030 & - & 0.035 & 0.115 \\
\hline DH1 & 0.06 & 0.65 & 0.045 & - & 0.035 & 0.115 \\
\hline DH4 & 0.06 & 1.25 & 0.070 & 0.025 & 0.035 & 0.325 \\
\hline DH5 & 0.06 & 1.25 & 0.080 & - & 0.035 & 0.325 \\
\hline AL1 & 0.05 & 0.35 & 0.035 & - & 0.043 & 0.010 \\
\hline DM1 & 0.06 & 0.70 & 0.050 & - & 0.051 & 0.070 \\
\hline
\end{tabular}

five $\mathrm{Nb}$ steels (DH1-DH5) were examined from the Dofasco (Canada) 7-stand hot strip mill, as well as one (AL1) from the Algoma (Canada) 6-stand, $2.69 \mathrm{~m}$ wide mill. Also examined were rolling data pertaining to a $\mathrm{Nb}$ steel (DM1) rolled on a German 7-stand hot strip mill (steel "DM1" in Ref. 5)). The chemical compositions of these steels are given in Table 1.

The MFS for each pass was calculated from the rolling data using the approach of Sims. ${ }^{9)}$ A computer spreadsheet was used for the MFS calculation that is similar to the spreadsheet for plate rolling described by Maccagno et al. ${ }^{10)}$ It was improved and adapted for hot strip mills by Siciliano et al. ${ }^{11)}$ The strip mill analysis incorporates the "forward slip" ratio so that the strip velocity and interpass time can be characterized more accurately; the "redundant" strains associated with flat rolling were also taken into account.

\subsection{Experimental Procedure}

Some laboratory tests were also conducted on the Sumitomo steels (SK1 and SK2) in order to obtain basic information about the flow behaviour of the $\mathrm{Nb}$ grades. The test were conducted using the McGill computerized hot torsion machine, which consists of a servo-hydraulic rotary actuator mounted on a lathe bed with specimen heating achieved using a microprocessor-controlled radiant furnace. Details of the control arrangements and data treatment are given in Ref. 10). The specimens were machined from the cropped ends of transfer bars. For all tests, the gauge length was $22.2 \mathrm{~mm}$ and gauge diameter was $6.4 \mathrm{~mm}$. The measured torque, $\Gamma$, and twist, $\theta$, were converted to von Mises effective stress and strain using the following formulas:

$$
\sigma=3.3 \sqrt{3} \cdot \Gamma /(2 \pi R), \quad \varepsilon=\theta R /(\sqrt{3} \cdot L)
$$

where $R$ and $L$ are the gauge radius and length of the specimen, respectively.

In order to obain the required MFS $v s .1 / T$ information, some of the torsion specimens were subjected to a series of 18 identical deformations separated by $3 \mathrm{sec}$ intervals, while they were cooled at $2^{\circ} \mathrm{C} / \mathrm{s}$. The strain for each deformation was $\varepsilon=0.4$ and the strain rate was $\dot{\varepsilon}=5 \mathrm{~s}^{-1}$. For all tests, the specimens were heated to $1200^{\circ} \mathrm{C}$ and held for $15 \mathrm{~min}$ before deformation. The specimens were then deformed in the temperature range from 1050 to $850^{\circ} \mathrm{C}$. In addition, some specimens were subjected to a single pass, large-strain torsion test. These test were carried out at constant temperatures of 950 and $1000^{\circ} \mathrm{C}$ and $\dot{\varepsilon}=5 \mathrm{~s}^{-1}$.
The MFS was taken to be the area under each $\sigma-\varepsilon$ curve divided by the strain. It was calculated by summing, over the entire deformation, the product of the strain increment $(\Delta \varepsilon)$ and the average stress developed during that increment $\left(\sigma_{\mathrm{av}}\right)^{10)}$ :

$$
\mathrm{MFS}=\sum \sigma_{\mathrm{av}} \Delta \varepsilon /\left(\varepsilon_{\mathrm{b}}-\varepsilon_{\mathrm{a}}\right)
$$

where $\varepsilon_{\mathrm{a}}$ and $\varepsilon_{\mathrm{b}}$ denote the beginning and end of the strain interval, respectively.

\section{Modeling of Microstructural Evolution for the Predic- tion of MFS}

\subsection{MFS Equation Based only on SRX}

Misaka's equation ${ }^{7)}$ has often been used to specify the MFS for C-Mn steels during hot strip rolling and was used here as the basis for a modified equation applicable to the $\mathrm{Nb}$ grades. The original Misaka MFS equation is as follows:

$$
\begin{aligned}
\sigma_{\mathrm{M}}= & \exp \left\{0.126-1.75[\mathrm{C}]+0.594[\mathrm{C}]^{2}\right. \\
& \left.+\left(2851+2968[\mathrm{C}]-1120[\mathrm{C}]^{2}\right) /(T+273)\right\} \varepsilon^{0.21} \dot{\varepsilon}^{0.13}
\end{aligned}
$$

where $\sigma_{\mathrm{M}}=$ the mean flow stress (in $\mathrm{kg} / \mathrm{mm}^{2}$ ), $[\mathrm{C}]=$ the carbon content (in wt $\%$ ), $T=$ the mean rolling temperature (in ${ }^{\circ} \mathrm{C}$ ), $\varepsilon=$ the strain, and $\dot{\varepsilon}=$ the strain rate (in $\mathrm{s}^{-1}$ ).

During strip rolling, the reductions are applied at various strains and strain rates, which makes it difficult to compare MFS values from one stand to the next. It is therefore useful, particularly in the present type of work, to "correct" them to constant values of strain and strain rate (e.g. $\left.\varepsilon=0.4, \dot{\varepsilon}=5 \mathrm{~s}^{-1}\right)$ by using the expression:

$$
\mathrm{MFS}_{\text {corr }}=\mathrm{MFS}_{\text {Sims }} \times\left(0.4 / \varepsilon_{\text {pass }}\right)^{0.21} \times\left(5 / \dot{\varepsilon}_{\text {pass }}\right)^{0.13}
$$

When the values of $\mathrm{MFS}_{\text {corr }}$ calculated in this way are plotted $v s .1 / T$, the temperature and "history" dependence of the MFS during strip rolling can be seen more clearly. This is shown in Fig. 1 for two of the Dofasco grades $(0.030 \mathrm{Nb}$ and $0.075 \mathrm{Nb})$. Also shown in this figure is the MFS calculated i) according to Misaka's equation (at $\varepsilon=0.4, \dot{\varepsilon}=5 \mathrm{~s}^{-1}$ ), and ii) according to Karjalainen $e t$ al.' $\mathrm{s}^{12)}$ equation. Here it is assumed that full SRX takes place between passes.

It is clear that the slopes of the Misaka and Karjalainen equations fit reasonably well with the mill log values in the region where the slope is quite shallow (i.e. at low $1 / T$ or high $T$ ). This indicates that full SRX is occurring between the passes in this region. Nevertheless the fit between the mill $\log$ and Misaka values in this region can be improved by modifying Eq. (3) to include the solution strengthening effects of $\mathrm{Nb}, \mathrm{Mn}$ and $\mathrm{Ti}$ :

$$
\mathrm{MFS}^{*}=\sigma_{\mathrm{M}}(0.768+0.51[\mathrm{Nb}]+0.137[\mathrm{Mn}]+4.217[\mathrm{Ti}])
$$

This equation fits the mill data of all grades very well, as can be seen from Figs. 1(a) and 1(b). (It should be noted that if sufficient data are available for a wide range of chemistries, terms can be added to the above relation for other alloying elements, such as $\mathrm{Mo}, \mathrm{Al}$, etc.) The experimental data from the 18-pass torsion testing of one of the Sumitomo $\mathrm{Nb}$ grades is also described well 


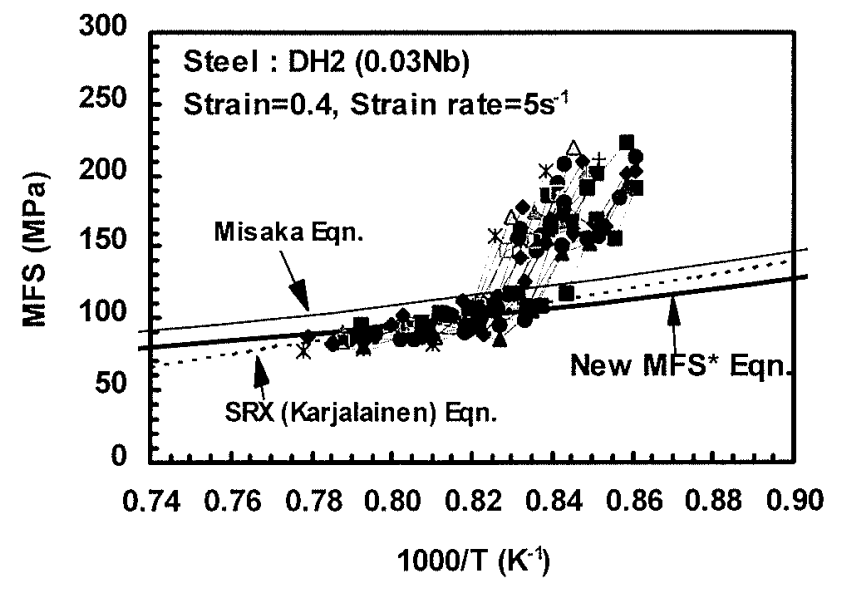

Fig. 1(a). MFS $v s .1 / T$ calculated from mill logs for steel $\mathrm{DH} 2$ $(0.03 \mathrm{wt} \% \mathrm{Nb})$, after correcting to a constant strain of 0.4 and strain rate of $5 \mathrm{~s}^{-1}$

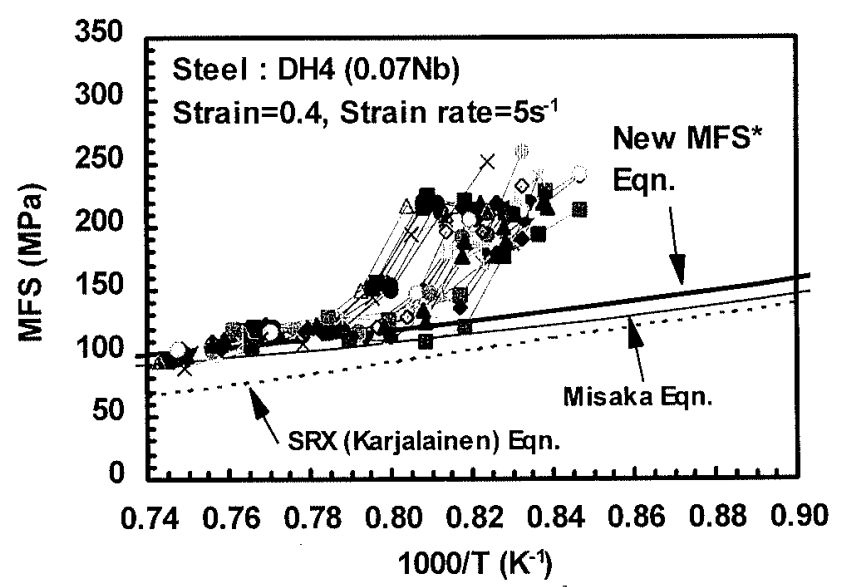

Fig. 1(b). MFS $v s .1 / T$ calculated from mill logs for steel DH4 $(0.07 \mathrm{wt} \% \mathrm{Nb})$, after correcting to a constant strain of 0.4 and strain rate of $5 \mathrm{~s}^{-1}$.

by Eq. (4), as illustrated in Fig. 2 (particularly in the early, high temperature, passes). It is apparent, however, that this improved Misaka equation is not able to specify the MFS behaviour in the "high slope" regions of Figs. 1 and 2 ; i.e. in the last few passes of rolling.

\subsection{An MFS Equation That Takes DRX into Account}

Both versions of Misaka's equation, as well as Karjalainen's equation, assume that full recrystallization takes place between passes. However, in Nb-containing steels, recrystallization is frequently incomplete when the interpass times are short, particularly during the later passes of strip rolling, when the temperature is relatively low. This leads to strain accumulation, which may in turn cause the initiation of dynamic recrystallization followed by metadynamic recrystallization. These three microstructural processes can be expected to contribute to the departures from the Misaka and other equations evident in Figs. 1 and 2.

The results of some large-strain torsion tests on the $0.036 \mathrm{wt} \% \mathrm{Nb}$ Sumitomo grade are compared with the MFS* prediction in Fig. 3. Note that, while the output of a torsion test is usually given in terms of stress $v s$. strain, the present analysis is expressed in terms of mean flow stress $v s$. strain. The experimental flow stresses were therefore converted into MFS values by evaluating Eq.

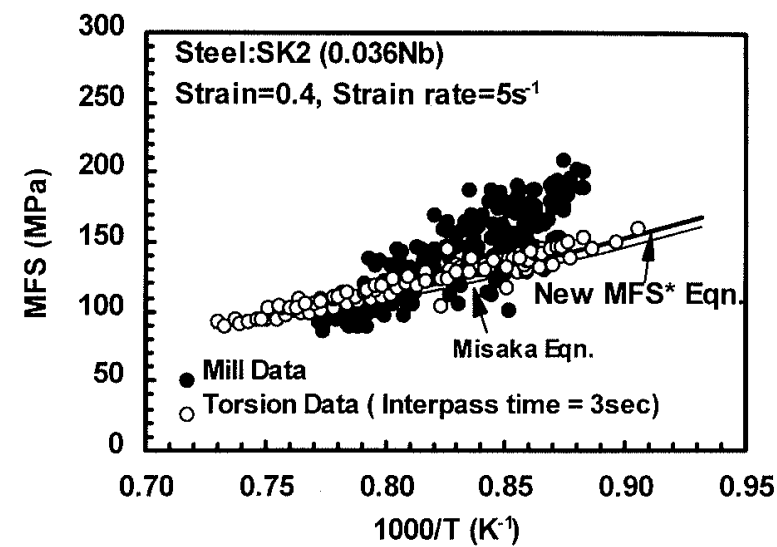

Fig. 2. Corrected MFS vs. $1 / T$ calculated from mill logs for steel SK2 $(0.036 \mathrm{wt} \% \mathrm{Nb})$, compared with that measured by 18 -pass torsion test.

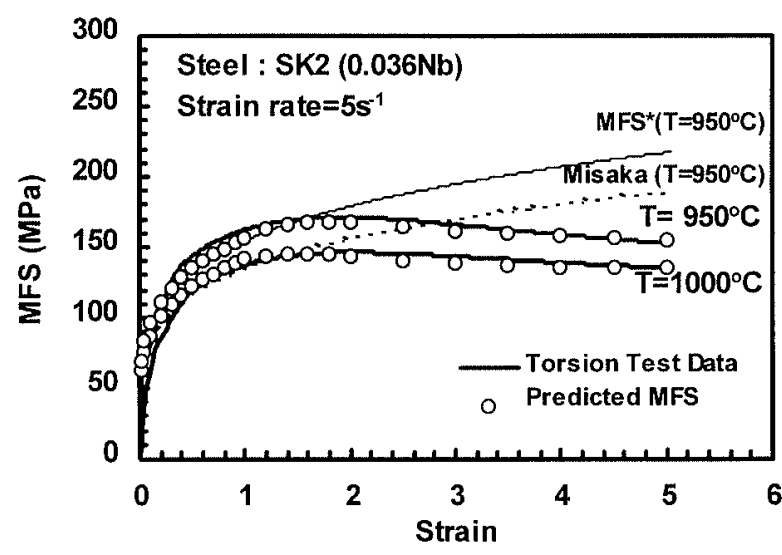

Fig. 3. Comparison between improved MFS predictions and single-pass torsion test results. Misaka's MFS* is higher than the measured MFS at high strains.

(2) over increments of $\Delta \varepsilon=0.02 .^{11)}$ Because MFS* is based on a simple power-law expression, it is evident that it cannot characterize the flow curve appropriately in the high strain range within which DRX becomes important.

Equation (5) was therefore modified by taking the effects of DRX into account. For this purpose, the DRX steady-state stress $\left(\sigma_{\mathrm{ss}}\right)$ was first described as follows ${ }^{13}$ ):

$$
\sigma_{\mathrm{ss}}=A\{\dot{\varepsilon} \exp (Q / R T)\}^{q}
$$

where $A$ and $q$ are parameters that depend on composition, and $Q$ is the activation energy for deformation. These values have been reported as $A=4.2, Q=375 \mathrm{~kJ} /$ mol and $q=0.09$ for $\mathrm{Nb}$ steels. ${ }^{13)}$ Then, following the approach of Senuma et al., ${ }^{14)}$ allowance was made for the fractional softening attributable to DRX as follows:

$$
X_{\mathrm{dyn}}=1-\exp \left[-0.693\left(\left(\varepsilon-\varepsilon_{\mathrm{c}}\right) / \varepsilon_{0.5}\right)^{2}\right], \quad \varepsilon>\varepsilon_{\mathrm{c}}
$$
and

$$
\varepsilon_{0.5}=1.144 \times 10^{-3} d_{0}^{0.25} \dot{\varepsilon}^{0.05} \exp (6420 / T)
$$

where $X_{\mathrm{dyn}}=$ the fractional softening attributable to DRX, $\varepsilon_{\mathrm{c}}=$ the DRX critical strain, $\varepsilon_{0.5}=$ the strain for $50 \%$ recrystallization, and $d_{0}=$ the initial grain size for each pass. The final MFS equation is obtained by combining Eqs. (5) to (8):

$$
\mathrm{MFS}=\operatorname{MFS}^{*}\left(1-X_{\mathrm{dyn}}\right)+K \sigma_{\mathrm{ss}} X_{\mathrm{dyn}}
$$


where the coefficient $K=1.14$ is a fitting parameter required to convert from stress to mean flow stress.* The MFS behaviour predicted using Eq. (9) leads to a good fit to the experimental results from the single pass torsion tests, as shown in Fig. 3.

\subsection{DRX Peak Strain Equation}

The critical strain $\left(\varepsilon_{\mathrm{c}}\right)$ required to initiate DRX is an important parameter in strip mill models. This is because the softening mechanism that is expected to operate after each pass, i.e. conventional SRX or MRX, will depend on whether the accumulation of pass strains is less than or greater than this value. The critical strain is often specified as a function of the peak strain for DRX, $\varepsilon_{\mathrm{p}}$. For plain carbon steels, the critical strain is widely regarded as being given by $\varepsilon_{\mathrm{c}}=0.8 \varepsilon_{\mathrm{p}}{ }^{15)}$ For $\mathrm{Nb}$ steels, the peak strain equation was examined by Roucoules et al. ${ }^{13)}$ However, their equation is not sensitive to the $\mathrm{Nb}$ concentration.

The peak strains measured by single-pass torsion tests carried out on Sumitomo grades SK 1 and SK2 are displayed in Fig. 4. Here it can be seen that the data for the $0.023 \mathrm{wt} \% \mathrm{Nb}$ steel deviate somewhat from the equation of Roucoules et al.; this can be attributed to the higher $\mathrm{Nb}$ content $(0.039 \mathrm{wt} \%)$ of the steel investigated by the latter workers. The peak strain equation was therefore modified on the basis of this figure so that it takes the $\mathrm{Nb}$ level into account. This led to the following new equation for the peak strain:

$$
\begin{aligned}
\varepsilon_{\mathrm{p}}= & (1+20[\mathrm{Nb}]) / 1.78 \times 2.8 \\
& \times 10^{-4} d_{0}^{0.5}\{\dot{\varepsilon} \exp (375000 / R T)\}^{0.17}
\end{aligned}
$$

The critical strain can be determined from Eq. (10) using the relation:

$$
\varepsilon_{\mathrm{c}}=C \varepsilon_{\mathrm{p}}
$$

Here $C$ is a constant equal to about 0.8 for $\mathrm{C}-\mathrm{Mn}$ steels and is somewhat lower for $\mathrm{Nb}$ grades, as will be seen in greater detail below. This relationship provides a reasonable description of the conditions associated with the initiation of DRX in hot working. (The reader should note, however, that in what follows no account is taken

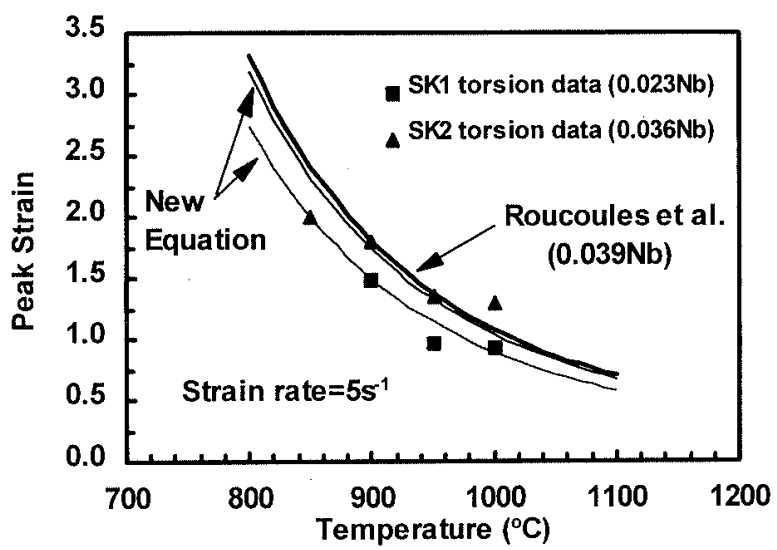

Fig. 4. Comparison between predicted (based on the equation of Roucoules et $a l .{ }^{13)}$ ) and measured peak strains from single-pass torsion tests carried out on steels SK 1 and SK2. of the different strain definitions that apply to plane strain rolling on the one hand and to axisymmetric deformation on the other.)

\subsection{Microstructural Evolution}

The approach taken here for characterizing the evolution of microstructure during strip rolling has been described previously for plain C-Mn grades. ${ }^{11}$ Using this approach, the accumulated strain that applies to each pass can be input into Eq. (9) to provide the MFS.

The fraction $X$ of recrystallized material present in a given pass can then be specified by the following Avrami equation:

$$
X=1-\exp \left[-B\left(t_{\mathrm{ip}} / t_{Y}\right)^{n}\right]
$$

where $t_{Y}$ is the time for a specified fraction of recrystallization $Y$ (say 0.5 ), which depends on whether the softening is by SRX or MRX and $B$ is equal to $-\ln (1-Y)$. The Avrami exponent $n=1$ for $\mathrm{Nb}$ grades. ${ }^{13)}$

\section{Static Recrystallization}

For the SRX of $\mathrm{Nb}$ steels, kinetic models that include a $\mathrm{Nb}$-dependent term have been proposed by Hodgson et al. ${ }^{16)}$ and Williams et al. ${ }^{17}$ The first model, developed for low $\mathrm{Nb}(0.01$ to $0.03 \mathrm{wt} \%)$ grades and strains of 0.3 and greater, is expressed as:

$$
\begin{aligned}
t_{0.5}= & (-5.24+550[\mathrm{Nb}]) 10^{-18} \varepsilon^{(-4.0+77[\mathrm{Nb}])} d_{0}^{2} \\
& \times \exp (330000 / R T) \quad \ldots \ldots \ldots \ldots \ldots \ldots \ldots \ldots \ldots \ldots \ldots \ldots \ldots \ldots \ldots \ldots
\end{aligned}
$$

By contrast, the model of Williams et al. was based on data obtained at higher strain rates $\left(4\right.$ to $\left.10 \mathrm{~s}^{-1}\right)$ on a two-high laboratory mill on steels containing 0.01 to $0.05 \mathrm{wt} \% \mathrm{Nb}$ that had been treated with small amounts of Ti. Their equations for $t_{0.25}$ are:

$$
\begin{aligned}
T>990^{\circ} \mathrm{C}, \quad t_{0.25}= & 1.5 \times 10^{-18} d_{0}^{2}(\varepsilon-0.025)^{-2.8} \\
& \times \exp (30[\mathrm{Nb}]) \exp (300000 / R T) \\
\ldots \ldots \ldots \ldots \ldots \ldots \ldots \ldots . . .(14) & \\
T<990^{\circ} \mathrm{C}, \quad t_{0.25}= & 1.0 \times 10^{-42} d_{0}^{2}(\varepsilon-0.025)^{-2.8} \\
& \times \exp (30[\mathrm{Nb}]) \exp (885000 / R T)
\end{aligned}
$$

where the relation applicable to temperatures above $990^{\circ} \mathrm{C}$ can be taken to refer to the solute drag regime, and the alternative relation describes the situation where strain-induced precipitation becomes important. The above empirical equations (Eqs. (13) to (15)) were used in this work when the accumulated effective strain was less than the $\varepsilon_{\mathrm{c}}$ for DRX.

Metadynamic Recrystallization

As far as discernible by the present authors, only Roucoules et al. ${ }^{13)}$ have quantified the MRX kinetics of $\mathrm{Nb}$ steels. The equation they proposed follows:

$$
t_{0.5}=4.42 \times 10^{-7} \dot{\varepsilon}^{-0.59} \exp (153000 / R T)
$$

This kinetic model includes a dependence on temperature and strain rate, but not on the strain. In the present study, Eq. (16) was used for MFS prediction when the accumulated effective strain was greater than $\varepsilon_{c}$.

\footnotetext{
* The constant 1.14 has nothing to do with converting from von Mises to plane strain. Instead, it is related to converting from a stress-strain curve to an MFS-strain curve. At large strains, this coefficient approaches 1.0 .
} 
Recrystallized Grain Size and Grain Coarsening

The grain sizes after full static recrystallization $\left(d_{\mathrm{SRX}}\right)$ observed in a number of steels have been shown to be functions of strain and initial grain size (in $\mu \mathrm{m}$ ) as follows ${ }^{18)}$ :

$$
d_{\mathrm{SRX}}=D \varepsilon^{-0.67} d_{0}^{0.67}
$$

The value of the constant $D$ varies considerably from author to author and falls in the range 0.9 to 1.9 for $\mathrm{Nb}$ steels. In this study, the value of $D$ was selected to be 1.9 because lower values were judged to give unrealistically fine recrystallized grain sizes.

The grain size after full metadynamic recrystallization $\left(d_{\mathrm{MRX}}\right)$ was represented by Roucoules et al. ${ }^{13)}$ as:

$$
d_{\mathrm{MRX}}=1400 \times\{\dot{\varepsilon} \exp (375000 / R T)\}^{-0.13}
$$

An interesting feature of this equation is that the recrystallized grain size does not depend at all on the original grain size.

Once recrystallization (SRX or MRX) is complete, grain coarsening takes place as a function of time and temperature. The grain coarsening equation for $\mathrm{Nb}$ steels given by Hodgson et al. ${ }^{16,19)}$ is:

$$
\begin{aligned}
d^{4.5}= & d_{\mathrm{SRX} \text { or MRX }}^{4.5}+4.1 \times 10^{23}\left(t_{\mathrm{ip}}-4.32 \times t_{0.5}\right) \\
& \times \exp (-435000 / R T) \quad \ldots \ldots \ldots \ldots \ldots \ldots \ldots \ldots \ldots \ldots \ldots
\end{aligned}
$$

where $t_{\mathrm{ip}}$ is the interpass time, and $4.32 \times t_{0.5}$ is the time for "full" $(95 \%)$ recrystallization (the factor 4.32 is calculated by Eq. (12) at $X=0.95$ ).

\section{Partial Recrystallization}

If only partial recrystallization takes place between passes, the average grain size at the entrance to the next stand can be calculated from a "law of mixtures" type relation that takes into account the softened and unaffected regions remaining from the previous pass ${ }^{20)}$ :

$$
d_{0 i+1}=X_{i}^{4 / 3} d_{\mathrm{RX} i}+\left(1-X_{i}\right)^{2} d_{0 i}
$$

where $d_{\mathrm{RX}}$ is determined by either Eq. (17) or (18), as appropriate.

Partial recrystallization also results in some strain being retained at the start of the next reduction; under these conditions the accumulated strain $\varepsilon_{\mathrm{a}}$ after the reduction is specified by the relation ${ }^{21)}$;

$$
\varepsilon_{\mathrm{ai}+1}=\varepsilon_{i+1}+k\left(1-X_{i}\right) \varepsilon_{i}
$$

where $k=1$ was used in this study for the $\mathrm{Nb}$ steels, and the strain calculated from the mill logs, $\varepsilon_{i}$, also includes the "redundant" strain. ${ }^{11)}$ These accumulated strain values were inserted into Eq. (11) to determine whether or not DRX was initiated during a given pass. The value for $\varepsilon_{\mathrm{a}}$ was also used in Eq. (9) to calculate the MFS for each pass.

\section{Results and Discussion}

MFS values for the present $\mathrm{Nb}$ steels were calculated using Eqs. (4) to (21), which had been combined into a single computer spreadsheet. This approach is similar to that described by Siciliano et al. ${ }^{11)}$ for $\mathrm{C}-\mathrm{Mn}$ steels. The predictions made in this way are compared below with the MFS values deduced from the rolling loads using the improved Sims approach outlined in Sec. 2.1.

The results for steels DH1 to DH5 and AL1, from two different hot strip mills, are presented in Fig. 5. In these calculations, the critical strain constant $C$ of Eq. (11) was set equal to 0.9. For the SRX softening kinetics, the equations developed by Hodgson et al. ${ }^{16)}$ and Williams et al. ${ }^{17)}$ were compared (Eq. (13), and Eqs. (14) and (15)). For all the data, the MFS values predicted using the equation of Williams et al. are closer to the observations than those obtained using Eq. (13). Moreover, it can be seen that only SRX occurs in all these steels under these rolling conditions. At no point is DRX initiated and followed by MRX.

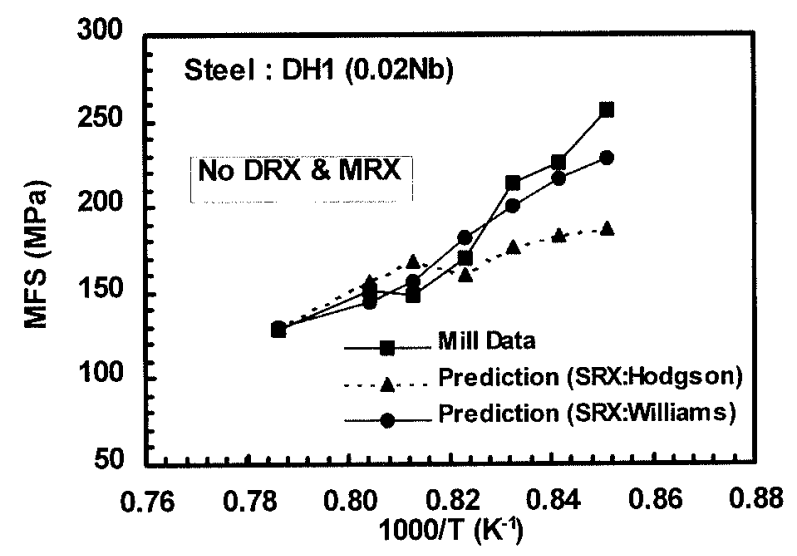

Fig. 5(a). Comparison of predicted and measured MFS values for steel DH1 $(0.02 \mathrm{wt} \% \mathrm{Nb})$.

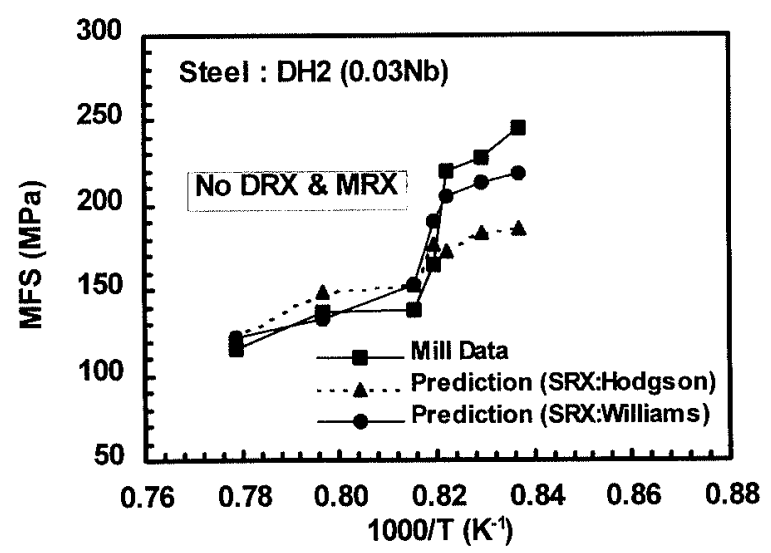

Fig. 5(b). Comparison of predicted and measured MFS values for steel $\mathrm{DH} 2(0.03 \mathrm{wt} \% \mathrm{Nb})$.

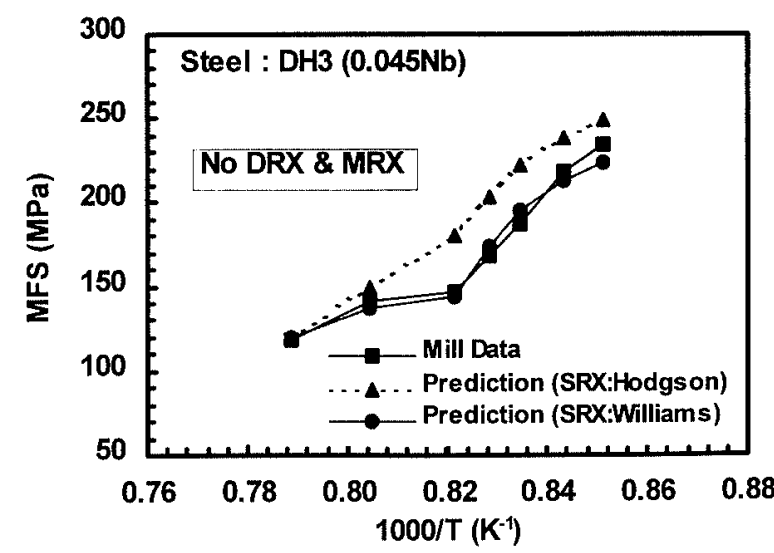

Fig. 5(c). Comparison of predicted and measured MFS values for steel $\mathrm{DH} 3(0.045 \mathrm{wt} \% \mathrm{Nb})$. 


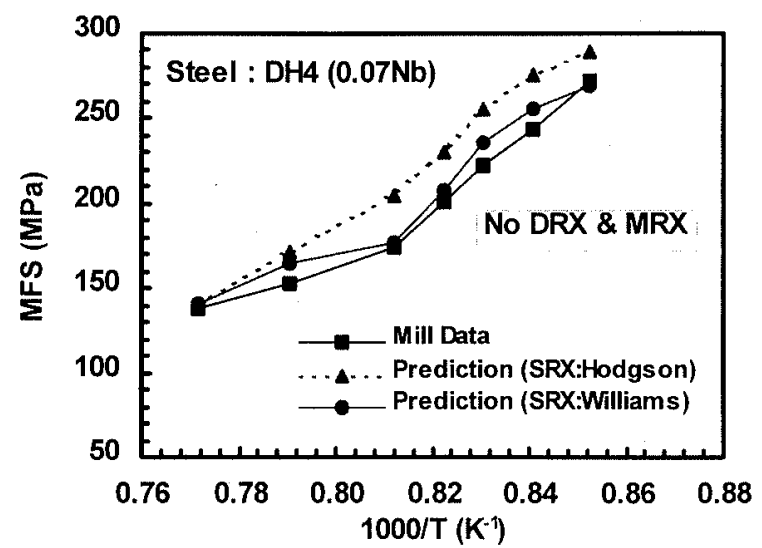

Fig. 5(d). Comparison of predicted and measured MFS values for steel DH4 $(0.07 \mathrm{wt} \% \mathrm{Nb})$

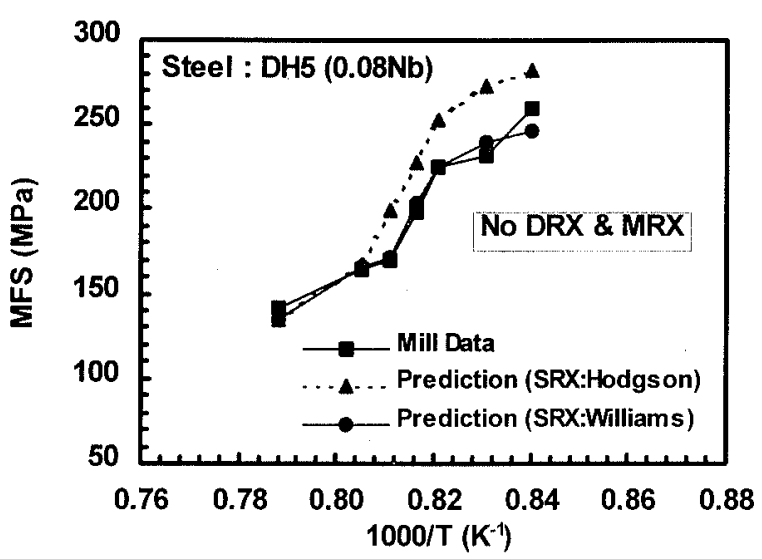

Fig. 5(e). Comparison of predicted and measured MFS values for steel $\mathrm{DH} 5(0.08 \mathrm{wt} \% \mathrm{Nb})$.

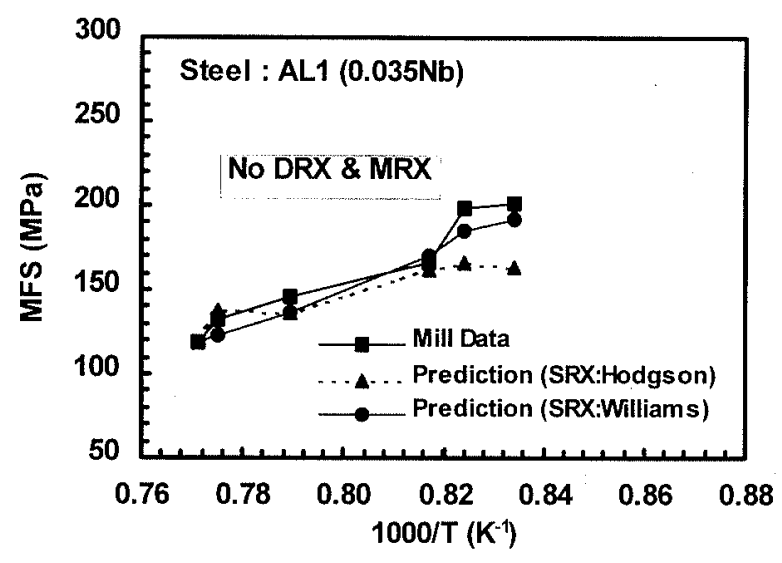

Fig. 5(f). Comparison of predicted and measured MFS values for steel AL1 $(0.035 \mathrm{wt} \% \mathrm{Nb})$.

The results from the other strip mills are illustrated in Fig. 6 (SK1, SK2 and DM1). Here, both sets of SRX softening equations (Eq. (13), and Eqs. (14) and (15)) were used in the calculations. Equation (13) was employed for the first few passes, where the strain rates are less than about $40 \mathrm{~s}^{-1}$ and the strain is greater than 0.3 , and Eq. (14) was employed for the later passes. It should be noted that in these predictions, the value of the critical strain constant $C$ of Eq. (11) had to be reduced to 0.6 in order to produce good agreement with the "actual" MFS values calculated from the mill logs. The significance of this lower value for the second set of steel

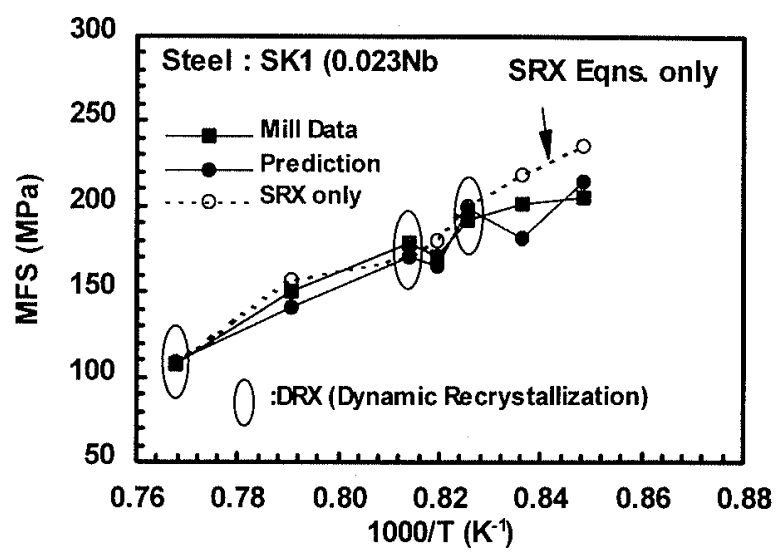

Fig. 6(a). Comparison of predicted and measured MFS values for steel SK1 $(0.023 \mathrm{wt} \% \mathrm{Nb})$. In this case, DRX and MRX occurred at several stands.

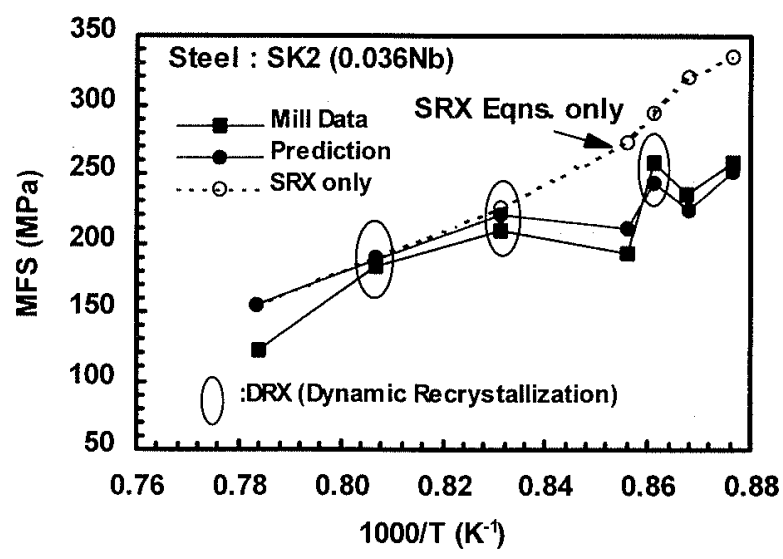

Fig. 6(b). Comparison of predicted and measured MFS values for steel SK2 $(0.036 w t \% \mathrm{Nb})$. In this case, DRX and MRX occurred at several stands.

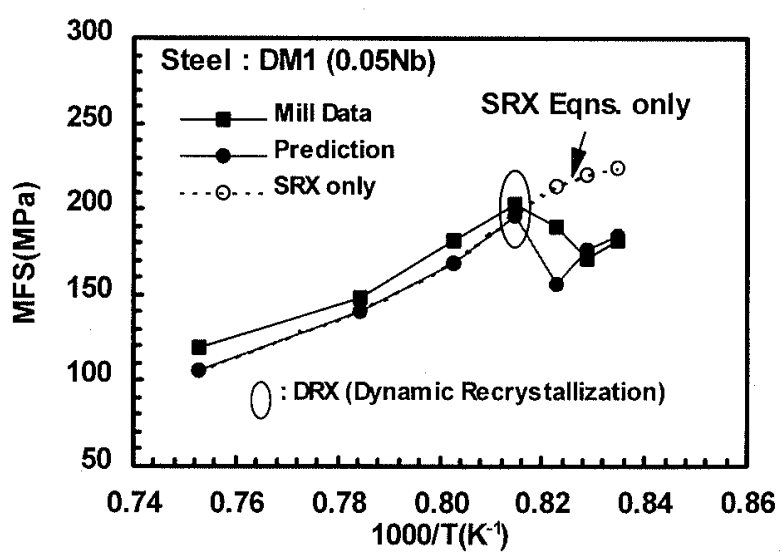

Fig. 6(c). Comparison of predicted and measured MFS values for steel DMI $(0.05 w t \% \mathrm{Nb})$. In this case, DRX and MRX occurred at one stand.

chemistries is discussed in more detail below. The predictions are again seen to be in good agreement with the actual MFS behaviour.

Of particular interest here is that DRX followed by MRX was indeed found to occur under the strip rolling conditions associated with steels SK1, SK2 and DM1. This was confirmed to be the case by comparing the MFS predictions obtained when only the SRX equations are used; i.e., if it is assumed that DRX followed by MRX is not possible (see Fig. 6). If only SRX is taken into 
account, the MFS values for the later passes are much higher than those observed in the mill. Note here, though, that even when only the SRX equations are employed, the fractional softening taking place between the final few passes is less than about $0.15-0.20$; i.e. there is no recrystallization of any type occurring, only recovery. The finding that DRX/MRX occurs in the DM1 steel was reported previously by Sarmento and Evans. ${ }^{5)}$ Several workers have suggested that the operation of these two mechanisms can lead to finer austenite grain sizes during hot strip rolling. ${ }^{2,4,5,8)}$

The conditions under which the 9 grades were rolled were all quite similar (see Table 2); nevertheless some grades exhibited DRX + MRX while others did not. For this reason, the parameters associated with the occurrence of MRX were examined in greater detail; they are summarized in Table 3. Here it can be seen that there are significant differences in the chemical compositions of the grades that are susceptible to these additional softening mechanisms. In particular, it appears that high levels of $\mathrm{Mn}$ (at least $1.0 \mathrm{wt} \%$ ) and low levels of $\mathrm{Si}$ (below $0.1 \mathrm{wt} \%$ ) favour the occurrence of

Table 2. Rolling conditions applicable to the steels studied.

\begin{tabular}{|c|c|c|c|c|c|c|c|c|c|c|c|}
\hline steel & stand & $\underset{\uparrow}{\text { strain }}$ & $\begin{array}{c}\text { strain } \\
\text { rate } \\
\text { t† } \\
\left(\mathrm{s}^{-1}\right)\end{array}$ & $\begin{array}{l}\text { temp. } \\
\left({ }^{\circ} \mathrm{C}\right)\end{array}$ & $\begin{array}{c}\text { inter- } \\
\text { pass } \\
\text { time } \\
\text { (sec) }\end{array}$ & steel & stand & strain & $\begin{array}{c}\text { strain } \\
\text { rate } \\
\text { at } \\
\left(\mathrm{s}^{-1}\right)\end{array}$ & $\begin{array}{l}\text { temp. } \\
\left({ }^{\circ} \mathrm{C}\right)\end{array}$ & $\begin{array}{c}\text { inter- } \\
\text { pass } \\
\text { time } \\
\text { (sec) }\end{array}$ \\
\hline \multirow[t]{7}{*}{ SK1 } & F1 & 0.72 & 13.1 & 1029 & 3.09 & \multirow[t]{7}{*}{ SK2 } & $\mathrm{Fl}$ & 0.83 & 13.9 & 1018 & 3.30 \\
\hline & F2 & 0.48 & 21.0 & 992 & 2.11 & & F2 & 0.53 & 23.2 & 981 & 2.19 \\
\hline & F3 & 0.42 & 33.6 & 956 & 1.52 & & F3 & 0.48 & 39.3 & 946 & 1.53 \\
\hline & $\mathrm{F} 4$ & 0.42 & 46.7 & 947 & 1.30 & & $\mathrm{~F} 4$ & 0.48 & 70.9 & 909 & 1.03 \\
\hline & F5 & 0.32 & 74.9 & 938 & 0.84 & & F5 & 0.32 & 89.0 & 901 & 0.79 \\
\hline & F6 & 0.29 & 103.1 & 923 & 0.64 & & F6 & 0.29 & 117.3 & 891 & 0.63 \\
\hline & F7 & 0.23 & 117.6 & 906 & - & & F7 & 0.18 & 116.5 & 878 & - \\
\hline \multirow[t]{7}{*}{$\mathrm{DHI}$} & $\mathrm{Fl}$ & 0.63 & 12.5 & 999 & 3.68 & \multirow[t]{7}{*}{$\mathrm{DH} 2$} & $\mathrm{Fl}$ & 0.74 & 13.6 & 1011 & 3.60 \\
\hline & $\mathrm{F} 2$ & 0.48 & 20.1 & 970 & 2.50 & & $\mathrm{~F} 2$ & 0.58 & 25.5 & 982 & 2.24 \\
\hline & F3 & 0.51 & 35.4 & 957 & 1.69 & & F3 & 0.58 & 48.8 & 953 & 1.41 \\
\hline & $\mathrm{F} 4$ & 0.34 & 47.5 & 942 & 1.27 & & F4 & 0.54 & 91.0 & 947 & 0.89 \\
\hline & F5 & 0.26 & 62.7 & 928 & 0.98 & & F5 & 0.36 & 139.2 & 943 & 0.59 \\
\hline & F6 & 0.23 & 77.1 & 915 & 0.77 & & F6 & 0.27 & 180.2 & 933 & 0.43 \\
\hline & F7 & 0.16 & 83.0 & 902 & - & & F7 & 0.17 & 199.8 & 922 & - \\
\hline \multirow[t]{7}{*}{ DH3 } & Fl & 0.57 & 13.2 & 995 & 3.38 & \multirow[t]{7}{*}{$\mathrm{DH} 4$} & F1 & 0.60 & 13.3 & 1023 & 3.50 \\
\hline & F2 & 0.47 & 21.1 & 970 & 2.32 & & $\mathrm{~F} 2$ & 0.50 & 22.2 & 992 & 2.35 \\
\hline & F3 & 0.46 & 34.2 & 944 & 1.63 & & F3 & 0.41 & 33.1 & 958 & 1.70 \\
\hline & F4 & 0.38 & 49.8 & 934 & 1.19 & & $\mathrm{~F} 4$ & 0.33 & 45.6 & 943 & 1.28 \\
\hline & F5 & 0.30 & 69.2 & 925 & 0.90 & & F5 & 0.30 & 65.2 & 931 & 0.98 \\
\hline & F6 & 0.23 & 82.9 & 913 & 0.70 & & F6 & 0.22 & 74.8 & 916 & 0.76 \\
\hline & F7 & 0.15 & 87.0 & 902 & - & & F7 & 0.13 & 74.7 & 900 & - \\
\hline \multirow[t]{7}{*}{ DH5 } & F1 & 0.61 & 13.3 & 996 & 3.53 & \multirow[t]{7}{*}{ ALl } & F1 & 0.81 & 16.7 & 1024 & 3.07 \\
\hline & F2 & 0.51 & 22.7 & 969 & 2.33 & & $\mathrm{~F} 2$ & 0.63 & 31.7 & 1017 & 1.89 \\
\hline & F3 & 0.54 & 41.8 & 960 & 1.52 & & F3 & 0.56 & 58.6 & 994 & 1.21 \\
\hline & $\mathrm{F} 4$ & 0.44 & 66.9 & 952 & 1.04 & & $\mathrm{~F} 4$ & 0.42 & 91.0 & 951 & 0.86 \\
\hline & F5 & 0.35 & 102.4 & 945 & 0.73 & & F5 & 0.32 & 114.6 & 940 & 0.67 \\
\hline & F6 & 0.25 & 125.0 & 931 & 0.55 & & $\mathrm{~F} 6$ & 0.21 & 121.1 & 926 & - \\
\hline & F7 & 0.13 & 120.5 & 917 & - & & - & - & - & - & $=$ \\
\hline
\end{tabular}

† These strains include the redundant strains. (See Section 2.1.)

†† These strain rates take into account the forward slip. (See Section 2.1.)

Table 3. Conditions associated with the initiation of DRX \& MRX during hot strip rolling

\begin{tabular}{|l|c|c|}
\hline & DRX \& MRX & No DRX \& MRX \\
\hline 1. Critical strain $\left(\varepsilon_{\mathrm{c}}\right)$ & $\varepsilon_{\mathrm{c}}=0.6 \varepsilon_{\mathrm{p}}$ & $\varepsilon_{\mathrm{c}}=0.9 \varepsilon_{\mathrm{p}}$ \\
\hline 2. Mn Content & High & Low \\
\hline 3. Si Content & Low & High \\
\hline
\end{tabular}

DRX and MRX. As high Mn levels have been shown to decrease the rate of recovery, it can be concluded that $\mathrm{Mn}$ addition increases the extent to which $\mathrm{Nb}$ addition is effective in preventing the occurrence of SRX. ${ }^{22,23)}$

It is readily apparent from the present analysis that the presence of Si decreases the probability that DRX can be initiated during strip rolling. One possible explanation of this behaviour is based on the opposing effects of $\mathrm{Mn}$ and $\mathrm{Si}$ on the kinetics of carbonitride precipitation. It is well known that $\mathrm{Mn}$ addition increases the solubility of carbonitrides, decreases the solution temperature, and retards the kinetics of precipitation. ${ }^{24)}$ Thus, no precipitation is expected during the strip rolling of high-Mn Nb steels that do not contain $\mathrm{Si}$; it is therefore possible to initiate DRX in these steels as a result of strain accumulation. Conversely, $\mathrm{Si}$ addition decreases the solubility of carbonitrides, increases the solution temperature, and accelerates the kinetics of precipitation. ${ }^{25)}$ Thus, precipitation becomes possible in Sicontaining materials, even during the scant six or seven seconds available during the first few passes of strip rolling. Such precipitation can clearly prevent DRX and MRX ${ }^{8)}$ In this way, the presence of Si can be considered to alter the behaviour of $\mathrm{Nb}$-containing steels from the idealized "strip mill" model (in which carbonitrides remain in solution) to a type of "plate mill" behaviour in which carbonitride precipitation becomes possible. Under the latter conditions, CCR (conventional controlled rolling) and pancaking take place in the strip mill as opposed to the DRCR + MDRCR behaviour ${ }^{8)}$ that applies when the $\mathrm{Mn}$ content is high and the Si content is low.

The key role played by the silicon level was confirmed by analyzing additional Dofasco mill logs pertaining to low $\mathrm{Si}$ versions of $\mathrm{DH} 2$ and $\mathrm{DH} 3$; these steels contained 0.030 and $0.045 \mathrm{wt} \% \mathrm{Nb}$, and about $0.65 \mathrm{wt} \% \mathrm{Mn}$, but the $\mathrm{Si}$ levels were reduced to less than $0.02 \mathrm{wt} \%$. In these cases, approximately half of the logs analyzed displayed DRX + MRX behaviour in the later passes, whereas none of the logs pertaining to DH2 and DH3 did so. If the $\mathrm{Mn}$ levels were closer to $1 \mathrm{wt} \%$, or higher, it is expected that DRX + MRX would have occurred in virtually all cases.

This reasoning also explains why low values of $C$ (e.g. $0.6)$ in the critical strain equation are associated with high $\mathrm{Mn}$ concentrations, while high $C$ values (e.g. 0.9 or even higher) are associated with presence of $\mathrm{Si}$. The increase in the $C$ value essentially indicates that the initiation of DRX is no longer possible when the Si level is high enough to provoke carbonitride precipitation.

The MFS model incorporating the evolution of austenite grain size and the occurrence or absence of DRX and MRX is in good general agreement with mill data, as can be seen from Fig. 7. The load estimates obtained from the model are within $\pm 15 \%$ of the observations for all steels, whether DRX occurs or not. Ouchi et al. ${ }^{26)}$ have reported a similarly good correspondence between measured and predicted mill loads in their modeling of the plate rolling of $\mathrm{Nb}$ grades. Their approach, however, requires knowledge of the "residual strain coefficient", which is determined by numerous laboratory tests 


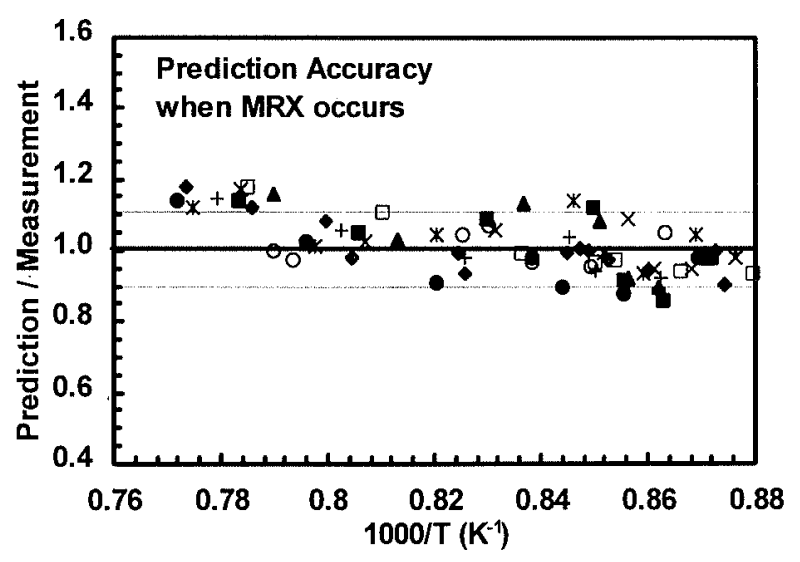

Fig. 7(a). Dependence on rolling temperature of the predictedto-measured MFS ratio. The 10 different symbols represent the data for 10 different bars of steels SKI, SK2 and DM1 (with MRX).

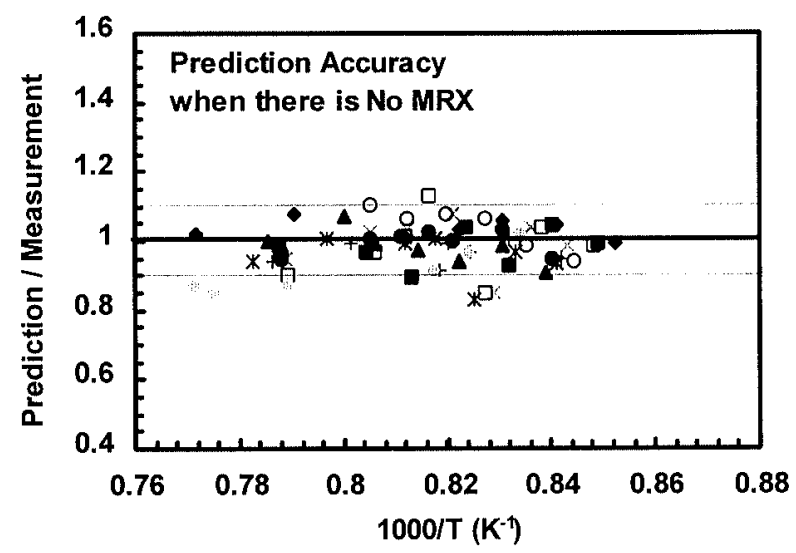

Fig. 7(b). Dependence on rolling temperature of the predictedto-measured MFS ratio. The 10 different symbols represent the data for 10 different bars of steels DH1-DH5 and AL1 (without MRX).

performed at the strain rates, strains, and temperatures pertaining to the mill of interest. While it is relatively easy to perform such tests at the strain rates applicable to plate mills (e.g. 1 to $10 \mathrm{~s}^{-1}$ ), it is considerably more difficult to generate reliable data at the rates relevant to strip mills (e.g. $100 \mathrm{~s}^{-1}$ and higher). The advantage of the present approach is that it makes use of general expressions describing the microstructural evolution at a more fundamental level, which are then configured appropriately to describe the behaviour in any type of mill. The present approach therefore appears to be useful for predicting both the microstructural characteristics as well as the MFS behaviours of $\mathrm{Nb}$ steels.

\section{Conclusions}

A mathematical model for the prediciton of mean flow stress (MFS) during the hot strip rolling of $\mathrm{Nb}$ steels was developed and tested using industrial rolling data from four different mills. The main results can be summarized as follows:

(1) A good understanding of the microstructural events that occur during the hot strip rolling of $\mathrm{Nb}$ grades can be obtained from mill logs if these are analyzed in terms of MFS vs. 1/T. For this purpose, the approach of Sims can be used to convert the rolling load into MFS, as long as the redundant strains and forward slips are taken into account.

(2) The peak strain associated with the occurrence of dynamic recrystallization in $\mathrm{Nb}$ containing steels can be characterized by including a term that reflects the $\mathrm{Nb}$ level. This expression is required for accurate prediction of the critical strain for the initiation of dynamic recrystallization.

(3) The MFS behaviour of previously undeformed (or recrystallized) Nb grades can be predicted by modifying the Misaka equation normally employed for C-Mn grades.

(4) The modified Misaka equation can be used to construct a strip mill model for rolling load by taking into account the $\mathrm{Nb}$ content, the extent of recrystallization between passes, the amount of strain accumulation, and the possibility that dynamic recrystallization occurs during a given pass. The predictions obtained from the model described here are in good agreement with mill observations.

(5) The model indicates that strain accumulation leading to dynamic recrystallization (followed by metadynamic recrystallization) occurs in the later passes of some of the $\mathrm{Nb}$ steels that were studied. When MFS predictions are made using only the SRX equations, the predicted MFS values are much higher in the later passes than those measured in the mill.

(6) Whether or not DRX + MRX occurs in a given hot strip mill depends on the $\mathrm{Mn}$ and $\mathrm{Si}$ levels (in addition to the $\mathrm{Nb}$ concentration). It appears that the strain accumulation required to initiate DRX is more likely to take place when the Mn level is high (greater than $1.0 \mathrm{wt} \%$ ) and the $\mathrm{Si}$ level is low (less than $0.1 \mathrm{wt} \%$ ). These observations can be taken to imply that carbonitride precipitation is absent under the above conditions. Conversely, the presence of Si levels above about 0.1 $\mathrm{wt} \%$ is likely to provoke precipitation during rolling and thus prevent the initiation and propagation of DRX.

\section{Acknowledgments}

The authors are indebted to Sumitomo Metal Industries Ltd., Dofasco Inc., and Algoma Steel Inc. for supplying the experimental materials and hot strip mill rolling data. They would like to express their special thanks to Mr. Brian Nelson of Dofasco and Mr. Brian McCrady of Algoma for their help. The financial support received from the Canadian Steel Industry Research Association (CSIRA) and the Natural Sciences and Engineering Research Council of Canada (NSERC) is acknowledged with gratitude. $\mathrm{KM}$ is indebted to Sumitomo Metal Industries Ltd., Kashima Steel Works, Japan, for providing a Visiting Fellowship. FS is grateful to the Conselho Nacional de Desenvolvimento Científico e Tecnológico, CNPq, Brazil, for the award of a Ph. D. scholarship.

\section{REFERENCES}

1) T. Senuma, M. Suehiro and H. Yada: ISIJ Int., 32 (1992), 423.

2) T. M. Maccagno, J. J. Jonas and P. D. Hodgson: ISIJ Int., 36 (1996), 720

3) C. Ouchi: Tetsu-to-Hagané, 70 (1984), 2081

4) F. H. Samuel, S. Yue, J. J. Jonas and K. R. Barnes: ISIJ Int., 
30 (1990), 216.

5) E. C. Sarmento and J. F. Evans: Proc. Int. Conf. on Processing, Microstructure and Properties of Microalloyed and Other High Strength Low Alloy Steels, Iron and Steel Soc. of AIME, Warrendale, USA, (1992), 105.

6) J. A. Biglou, B. D. Nelson, D. R. Hall and J. G. Lenard: Proc 37th Mechanical Working and Steel Processing Conf., ISS of AIME, Warrendale, USA, (1995), 661.

7) Y. Misaka and T. Yoshimoto: J. Jpn. Soc. Technol. Plast., 8 (1967-8), 414.

8) J. J. Jonas: Mater. Sci. Eng., A184 (1994), 155.

9) R. B. Sims: Proc. Inst. Mech. Eng., 168 (1954), 191

10) T. M. Maccagno, J. J. Jonas, S. Yue, B. J. McCrady, R. Slobodian and D. Deeks: ISIJ Int., 34 (1994), 917.

11) F. Siciliano Jr., K. Minami, T. M. Maccagno and J. J. Jonas: ISIJ Int., 36 (1996), 1500

12) L. P. Karjalainen, T. M. Maccagno and J. J. Jonas: ISIJ Int., 35 (1995), 1523

13) C. Roucoules, S. Yue and J. J. Jonas: Proc. Int. Conf. on Modeling of Metal Rolling Processes, The Inst. of Materials, London, UK, (1993), 165.

14) T. Senuma, H. Yada, Y. Matsumura and T. Futamura: Tetsu-toHagané, 70 (1984), 2112.

15) C. M. Sellars: Mater. Sci. Technol., 6 (1990), 1072.
16) P. D. Hodgson and R. K. Gibbs: ISIJ Int., 32 (1992), 1329.

17) J. G. Williams, C. R. Killmore and G. R. Harris: Proc. Int. Conf. on Physical Metallurgy of Thermomechanical Processing of Steels and Other Metals (THERMEC '88), ISIJ, Tokyo, (1988), 224

18) C. M. Sellars: Proc. Int. Conf. on Hot Working and Forming Processes, The Met. Soc., London, (1980), 3.

19) M. Pietrzyk, C. Roucoules and P. D. Hodgson: ISIJ Int., 35 (1995), 531.

20) J. H. Beynon and C. M. Sellars: ISIJ Int., 32 (1992), 359.

21) R. K. Gibbs, P. D. Hodgson and B. A. Parker: Proc. Int. Conf. on Recrystallization in Metallic Materials (Recrystallization '90), Metall. Soc. of AIME, Warrendale, USA, (1990), 585.

22) J. J. Jonas and M. G. Akben: Met. Forum, 4 (1981), 92.

23) C. Ouchi, T. Okita, M. Okada and Y. Noma: Proc. Int. Conf. on Steel Rolling, ISIJ, Tokyo, (1980), 1272.

24) M. G. Akben, I. Weiss and J. J. Jonas: Acta Metall., 29 (1981), 111

25) R. W. K. Honeycombe and H. K. D. H. Bhadeshia: SteelsMicrostructures and Properties, 2nd ed. Edward Arnold, London, (1995), 60.

26) C. Ouchi, T. Okita, T. Ichihara and Y. Ueno: Trans. Iron Steel Inst. Jpn., 20 (1980), 833. 